Article

\title{
Thermodynamic Properties and State Diagram of Gum Ghatti-Based Edible Films: Effects of Glycerol and Nisin
}

\author{
Pingping Zhang ${ }^{1,+}{ }^{,}$Ya Zhao ${ }^{1,+}$, Xin Zhang ${ }^{1}$, Lanlan Zhu ${ }^{1}$, Zhongxiang Fang ${ }^{2} \oplus$ and \\ Qilong Shi 1,* \\ 1 School of Agricultural Engineering and Food Science, Shandong University of Technology, Xincun West \\ Road, Zibo, Shandong 255000, China \\ 2 School of Agriculture and Food, The University of Melbourne, Parkville 3010, Australia \\ * Correspondence: shiqilong2006@hotmail.com or qilongshi@sdut.edu.cn \\ + Pingping Zhang and Ya Zhao contributed equally to this work and are co-first authors.
}

Received: 14 January 2020; Accepted: 11 February 2020; Published: 14 February 2020

\begin{abstract}
In this present study, the thermodynamic and thermal properties of glycerol and nisin-incorporated gum ghatti (GG, Anogeissus latifolia)-based films were determined. The films exhibited type III isotherm behaviors. Moisture content (MC) of films was increased with increasing water activity $\left(a_{\mathrm{w}}\right)$ and decreased with higher temperature. The incorporation of glycerol and nisin increased the sorption ability of GG films. The net isosteric heat of adsorption $\left(q_{\mathrm{st}}\right)$ and differential entropy $\left(S_{\mathrm{d}}\right)$ were decreased with increasing $\mathrm{MC}$, showing an exponential negative correlation between them. Spreading pressure $(\varphi)$ was increased with increasing $a_{\mathrm{w}}$, but decreased with higher temperature. This incorporation of glycerol and nisin increased the $q_{\mathrm{st}}, S_{\mathrm{d}}$ and $\varphi$ of the GG films. The sorption behaviors were enthalpy-driven and non-spontaneous processes. The glass transition temperature $\left(T_{\mathrm{g}}\right)$, critical MC and $a_{\mathrm{w}}$ of the films were decreased, and increased respectively with the incorporation of glycerol and nisin. This work provides a theoretical basis for the application of edible films in fresh food preservation.
\end{abstract}

Keywords: gum ghatti; glycerol; nisin; thermodynamic properties; state diagram

\section{Introduction}

Numerous researches have been performed recently in the development of edible and biodegradable packaging materials from natural biopolymers because of consumers' increased health and environmental concerns induced by synthetic plastic [1,2]. Gum ghatti (GG) is the sap collected from the tree Anogeissus latifolia/indifolia, which is mainly grown in India [3]. In a previous study, Zhang, Zhao and Shi [4] suggested that GG has a great potential in edible film fabrication with anticipated features, such as an excellent barrier, along with mechanical, optical and structural properties.

As a packaging material, edible films' ability to restrict the moisture transfer between the food and its surrounding environment is an important attribute [5]. The adsorbed water will interfere with the films' physical and mechanical characteristics and give rise to considerable performance deterioration when the moisture content $(\mathrm{MC})$ of films reaches a critical value [6,7]. Therefore, it is extremely important to reveal the water change rules under various ambient conditions, such as temperature and relative humidity $(\mathrm{RH})$. Water activity $\left(a_{\mathrm{w}}\right)$ implies the 'quality' of water content, and exhibits the bound degree of water, which is important to evaluate the availability of water involved in physical, chemical and microbial reactions [8]. The moisture sorption isotherm (MSI) reveals the relevance of equilibrium moisture content (EMC) and $a_{\mathrm{w}}$ or equilibrium-relative humidity (ERH) under a specific 
temperature and pressure [8]. Moisture thermodynamics are derived from isotherm data and regarded as a dependable guideline to estimate physical properties and the storage stability of foods $[9,10]$.

Thermodynamic parameters include the net isosteric heat of sorption $\left(q_{\mathrm{st}}\right)$, differential entropy $\left(S_{\mathrm{d}}\right)$, spreading pressure $(\varphi)$, and the enthalpy-entropy compensation theory $[6,7]$. The $q_{\mathrm{st}}$ value implies the binding strength between water and food solid (by intermolecular attraction forces between sorbate and adsorptive sites); $S_{\mathrm{d}}$ is proportional to the number of available adsorption sites at a determined energy level; $\varphi$ or surface potential signifies the excess free energy of the surface, and means the increase of surface tension of bare adsorption sites as a result of adsorbed molecules; enthalpy-entropy compensation theory (also termed as the isokinetic theory) is useful to acquire information concerning the mechanisms that dominate the moisture adsorption process $[9,10]$.

Glass transition theory is commonly used to describe the relationship of biopolymers' structure and its properties, as well as their relevance to food processing and preservation [5]. The glass transition theory is of vital importance to the edible film field, since the films' mechanical and barrier characteristics are significantly affected by the glass transition temperature $\left(T_{\mathrm{g}}\right)$ of the film matrix [11]. State diagram, the most valuable application of $T_{\mathrm{g}}$, is graphical explanations of the physical states of food ingredients in regard to temperature and the moisture/solid content at a determined pressure, and it can be adopted to reveal the complex physical and chemical variations that emerged in foods, and select suitable processing/storage conditions of food systems [12,13].

In biopolymer film preparation, plasticizers are usually added to interact with the polymer chains, which are competent for orienting them between the chains of polymers, and interfering with the interactions between polymers accompanying the improvement of molecular mobility, flexibility and processability [14]. To satisfy consumers' demand for the high efficiency of food preservation, active antimicrobial packaging films have been developed $[2,15]$. Antimicrobial films are commonly achieved by adding antimicrobial agents (such as nisin) into films, forming matrices $[16,17]$. However, the performance for hydrophilic films are markedly altered owing to the plasticization effects, either when the films are placed under different values of RH during transportation and storage, or the films was incorporated with plasticizers and antimicrobial agents [18]. However, little attention has been paid to the thermodynamic properties and state diagram of edible films, especially GG-based films. Therefore, the purposes of this work were to investigate the effect of glycerol and nisin on the adsorption characteristics and thermodynamic properties, together with the state diagram of films, and evaluate the performance of GG-based films, utilizing critical parameters, viz. critical $a_{\mathrm{w}}$ and critical MC, based on the state diagram.

\section{Material and Methods}

\subsection{Materials}

Gum ghatti, glycerol and nisin were acquired from Shanghai Quanwang Biotechnology Co. Ltd. (Shanghai, China). Inorganic salts used for relative humidity $(\mathrm{RH})$ control include $\mathrm{LiCl}, \mathrm{CH}_{3} \mathrm{COOK}$, $\mathrm{MgCl}_{2}, \mathrm{~K}_{2} \mathrm{CO}_{3}, \mathrm{Mg}\left(\mathrm{NO}_{3}\right)_{2}, \mathrm{NaNO}_{2}, \mathrm{NaCl}, \mathrm{KCl}$ and $\mathrm{BaCl}_{2}$, which were of analytical grade and obtained from Tianjin Reagent Chemicals Co. Ltd. (Tianjin, China).

\subsection{Preparation of Films}

Pure gum ghatti (GG) film (GG-P), GG film with the incorporation of glycerol (GG-G), and GG film with an incorporation of glycerol and nisin (GG-G-N) were prepared according to Zhang et al. [4] and Zhao, Zhang and Shi [19]. Briefly, aqueous solutions of 0.75\% GG were prepared under 15-min constant stirring at ambient temperature. GG molecules were dispersed and fully hydrated using a disperser (Ultra-Turrax, IKA T18, IKA-Werke Gmbh \& Co. KG, Staufen, Germany). The solution was kept at $40{ }^{\circ} \mathrm{C}$ for $60 \mathrm{~min}$ in a thermostatic water bath. After that, film-forming solution was divided into three equal parts: (1) a control GG-P solution without the incorporation of plasticizer and antimicrobial agent; (2) a GG-G solution with addition of $30 \%$ (w/w, based on GG weight) glycerol into the GG 
solution; (3) a GG-G-N solution with addition of 10\% (w/w, based on GG weight) nisin into the GG-G solution. To remove air bubbles, the three film-forming solutions were then put into an ultrasonic apparatus (SK3310LHC, Kudos Ultrasonic Instrument Co., Ltd., Shanghai, China) for 60 min. Finally, the solutions were respectively casted on Petri dishes and heat pump dried (1HP-5, Qingdao Oumeiya Technology Co. Ltd., Qingdao, China) at $25^{\circ} \mathrm{C}$ for $24 \mathrm{~h}$. The resulting films were peeled off from the casting surface.

\subsection{Moisture Sorption Isotherms}

Triplicate film samples were placed into airtight desiccators and equilibrated with various saturated salt solutions to obtain $a_{\mathrm{w}}$ ranging from 0.113 to 0.931 [20,21], and the values are shown in Table 1 . The desiccators were put into incubators with set temperatures (viz., 5,15 and $25^{\circ} \mathrm{C}$ ). Weighing the samples regularly until constant weight was attained. Moisture content of the samples was obtained by drying in an electric oven (DHG-9140A, Yiheng Scientific Instrument Co., Ltd., Shanghai, China) at $90^{\circ} \mathrm{C}$ for $24 \mathrm{~h} \mathrm{[4]}$.

Table 1. Water activity of selected saturated salt solution at 5,15 and $25^{\circ} \mathrm{C}$.

\begin{tabular}{cccc}
\hline \multirow{2}{*}{ Saturated Salt Solutions } & \multicolumn{3}{c}{ Temperature $\left({ }^{\circ} \mathbf{C}\right)$} \\
\cline { 2 - 4 } & $\mathbf{5}$ & $\mathbf{1 5}$ & $\mathbf{2 5}$ \\
\hline $\mathrm{LiCl}$ & 0.113 & 0.113 & 0.113 \\
$\mathrm{CH}_{3} \mathrm{COOK}$ & 0.235 & 0.234 & 0.225 \\
$\mathrm{MgCl}_{2}$ & 0.336 & 0.333 & 0.328 \\
$\mathrm{~K}_{2} \mathrm{CO}_{3}$ & 0.431 & 0.432 & 0.432 \\
$\mathrm{Mg}\left(\mathrm{NO}_{3}\right)_{2}$ & 0.589 & 0.559 & 0.529 \\
$\mathrm{NaNO}_{2}$ & 0.693 & 0.693 & 0.654 \\
$\mathrm{NaCl}_{\mathrm{KCl}}$ & 0.757 & 0.756 & 0.753 \\
$\mathrm{BaCl}$ & 0.877 & 0.859 & 0.843 \\
& 0.931 & 0.915 & 0.903 \\
\hline
\end{tabular}

The moisture sorption isotherm data of GG-based films were fitted to Guggenheim-Anderson-De Boer (GAB) (Equation (1)) and the Halsey model (Equation (2)) [22].

$$
\begin{gathered}
X=\frac{X_{m g} C_{g} K a_{w}}{\left(1-K a_{w}\right)\left(1-K a_{w}+C_{g} K a_{w}\right)} \\
X=\left(\frac{-a}{\ln a_{w}}\right)^{\frac{1}{r}}
\end{gathered}
$$

where $X$ is moisture content (dry basis, d.b.); $X_{m g}$ is the GAB monolayer moisture content; $C_{g}, K, a$ and $r$ are constants.

The model fit precision was judged by the coefficient of determination $\left(R^{2}\right)$ and the standard error of estimate (SE) between the experimental and predicted data using Equation (3) [13].

$$
S E=\sqrt{\frac{\sum_{i=1}^{N}\left(X_{\mathrm{e}, \mathrm{i}}-X_{\mathrm{p}, \mathrm{i}}\right)^{2}}{N-n}}
$$

where $N$ and $n$ are the number of experimental observation and the number of constants in each model, respectively; $X_{\mathrm{e}, \mathrm{i}}$ and $X_{\mathrm{p}, \mathrm{i}}$ are the experimental and predicted moisture contents, respectively. 


\subsection{Thermodynamic Properties}

2.4.1. Net Isosteric Heat of Sorption $\left(\mathrm{q}_{\mathrm{st}}\right)$ and Differential Entropy $\left(\mathrm{S}_{\mathrm{d}}\right)$

The $q_{\text {st }}$ can be deduced from sorption isotherm data by Clausius-Clapeyron equation [23]:

$$
q_{s t}=-R\left(\frac{d \ln a_{\mathrm{w}}}{d(1 / T)}\right)_{X}
$$

where $R$ is the universal gas constant, $8.314 \mathrm{~J} /(\mathrm{mol} \cdot \mathrm{K}) ; T$ is the sorption temperature $(K) ; a_{\mathrm{w}}$ is water activity; $X$ is moisture content (d.b.).

By plotting $\ln a_{\mathrm{w}}$ versus $1 / T$ at determined moisture content, then $q_{\mathrm{st}}$ can be calculated from the slope.

The relationship between $q_{\mathrm{st}}$ and $S_{\mathrm{d}}$ is given by Equation (5) [24].

$$
\left.\ln a_{\mathrm{w}}\right|_{X}=-\frac{q_{\mathrm{st}}}{R T}+\frac{S_{\mathrm{d}}}{R}
$$

By plotting $\ln a_{\mathrm{w}}$ versus $1 / T$ at constant moisture content, then $S_{\mathrm{d}}$ can be calculated from the intercept.

\subsubsection{Enthalpy-Entropy Compensation Theory}

The compensation theory proposes a linear relationship between $Q_{s t}$ and $S_{d}$ [25]:

$$
Q_{\mathrm{st}}=T_{\beta} S_{\mathrm{d}}+\Delta G_{\beta}
$$

where $Q_{\text {st }}$ is the isosteric heat of sorption, the value of which is $q_{\text {st }}$ plus the heat of vaporization of water at the system temperature; $T_{\beta}$ is the isokinetic temperature $(K)$, representing the temperature at which all the reactions proceed at the same rate; $\Delta G_{\beta}$ is the Gibbs' free energy at $T_{\beta}(\mathrm{J} / \mathrm{mol})$.

By plotting $Q_{\text {st }}$ against $S_{\mathrm{d}}, T_{\beta}$ and $\Delta G_{\beta}$ can be obtained by linear regression.

Comparison between $T_{\beta}$ and harmonic mean temperature $\left(T_{\mathrm{hm}}\right)$ can be used to verify the validity of the compensation theory; and the compensation theory exists only when $T_{\beta} \neq T_{\mathrm{hm}}$ [26]. The sorption process is enthalpy-driven if $T_{\beta}>T_{\mathrm{hm}}$, and is entropy-driven if $T_{\beta}<T_{\mathrm{hm}}$ [27]. $T_{\mathrm{hm}}$ is defined as:

$$
T_{\mathrm{hm}}=\frac{n}{\sum_{i=1}^{n}\left(1 / T_{i}\right)}
$$

where $n$ is the number of sorption isotherms employed.

\subsubsection{Spreading Pressure $(\varphi)$}

The $\varphi$ was determined using the equation described by Moreira et al. [23]:

$$
\varphi=\frac{K_{B} T}{A_{m}} a^{\frac{1}{r}}\left(\frac{1}{\left(\frac{1}{r}-1\right)\left(-\ln a_{\mathrm{W}}\right)^{\frac{1}{r}-1}}\right)_{0.05}^{a_{\mathrm{W}}}
$$

where $K_{\mathrm{B}}$ is Boltzmann's constant $\left(1.38 \times 10^{-23} \mathrm{~J} / \mathrm{K}\right) ; A_{\mathrm{m}}$ is the surface area of a water molecule $\left(1.06 \times 10^{-19} \mathrm{~m}^{2}\right) ; a$ and $r$ are the constants of Halsey equation (Equation (2)).

\subsection{Glass Transition Temperature $\left(T_{g}\right)$}

The $T_{\mathrm{g}}$ of films equilibrated at different RHs was analyzed using a differential scanning calorimetry (DSC) (Q100, TA Instruments, New Castle, DE, USA). A single scanning program was adopted for the analysis of $T_{\mathrm{g}}$ [13]. Briefly, samples $(5 \sim 10 \mathrm{mg})$ were enclosed in hermetically sealed aluminum 
pans and placed on the DSC. The sample was scanned between -100 and $200{ }^{\circ} \mathrm{C}$ at $10^{\circ} \mathrm{C} / \mathrm{min}$. The midpoint of the glass transition was chosen as the characteristic's temperature of transition.

The relationship between the $T_{\mathrm{g}}$ and water of GG-based films can be described by the Gordon-Taylor equation [13].

$$
T_{g}=\frac{\left(1-X_{w}\right) T_{g s}+k X_{w} T_{g w}}{\left(1-X_{w}\right)+k X_{w}}
$$

where $T_{\mathrm{g}}, T_{\mathrm{gs}}$ and $T_{\mathrm{gw}}$ are the glass transition temperature of film samples, film solids and water, respectively; $X_{\mathrm{W}}$ is the mass fraction of water; $k$ is the model parameter.

\subsection{Statistical Analysis}

Model parameters were achieved by non-linear regression analyses (Matlab 7.0 software, MathWorks Corp., Natick, MA, USA). The analysis of variance (ANOVA) was carried out by SPSS software (Version 17.0, SPSS Inc., Chicago, IN, USA) and Duncan's multiple range test was selected to evaluate the significant differences $(p<0.05)$.

\section{Results and Discussion}

\subsection{Moisture Sorption Isotherm}

Figure 1 shows the isotherm plots at 5,15 and $25^{\circ} \mathrm{C}$, from which the effect of plasticizer (glycerol) and antimicrobial agent (nisin) on the sorption characteristics of GG-based films was observed. GG-based films followed typical type III sorption behaviors. The EMC was increased with increasing $a_{\mathrm{w}}$ at a given temperature, which can be attributed to the films' tendency of lowering the vapor partial pressure as the RH of ambient air was decreased [28]. The EMC of GG-based films was decreased with higher temperature at determined $a_{\mathrm{w}}$, as shown in Figure 1a-c. This tendency could be interpreted by the activation state of molecules. The molecule-molecule attractive forces are decreased with increasing temperature, owing to an increase in the kinetic energy, which results in an increased mutual distance of water molecules [9]. Consequently, water molecules became less stable, and easily run away from the binding sites [7]. It was noted that at the employed temperature range (viz. $5-25^{\circ} \mathrm{C}$ ), a tendency to crossover at $a_{\mathrm{w}}>0.85$ can be observed from the MSI of GG-based films. The crossover behavior during the moisture sorption of polymers is mainly attributed to the over-exposure of the active sites and/or hydrophilic groups under higher $a_{\mathrm{w}}$ conditions with the increase of temperature [29]. Similar observations have been reported for MSI of pure alginate films [7].

In Figure 1d, the EMC of all three films was slowly increased until $a_{\mathrm{w}}$ approaches 0.60, afterwards a marked increase in EMC was observed, especially for films with glycerol and nisin (GG-G-N). At a constant $a_{\mathrm{w}}$ and temperature, pure GG film had the lowest EMC, whereas an addition of glycerol and nisin increased the film moisture sorption capacity. This trend was more obvious especially at $a_{\mathrm{w}}>0.60$. This might be due to the dual plasticization effects of glycerol and the water molecule. This phenomenon also implied that glycerol was more hydrophilic than nisin. The addition of glycerol to GG films enhanced the hygroscopic nature of the film, which can be attributed to the low molecular weight and polar solute characteristics of glycerol [5]. However, the reason for the increased hygroscopic nature of GG-G-N might be due to the exposure of hydrophilic groups during film formation and moisture sorption procedures.

Fitting the sorption isotherm models to the experimental data of GG-based films is shown in Table 2. As can be observed, the GAB and Halsey models correlated well to the water sorption isotherm data over the whole range of temperatures, and $a_{\mathrm{W}}$ investigated due to higher $R^{2}$ and lower $S E$ values. However, it should be noted that merely higher $R^{2}$ and lower $S E$ values are not enough to guarantee the statistically validity of model fitting. Residual plots were then analyzed at different temperatures. Among the selected models, the Halsey model provided a scattered or random residual 
pattern (Table 2). Therefore, the Halsey model is suitable for expounding the sorption behavior for GG-based films at temperature and the $a_{\mathrm{w}}$ range of $5-25^{\circ} \mathrm{C}$ and $0.113-0.931$, respectively.
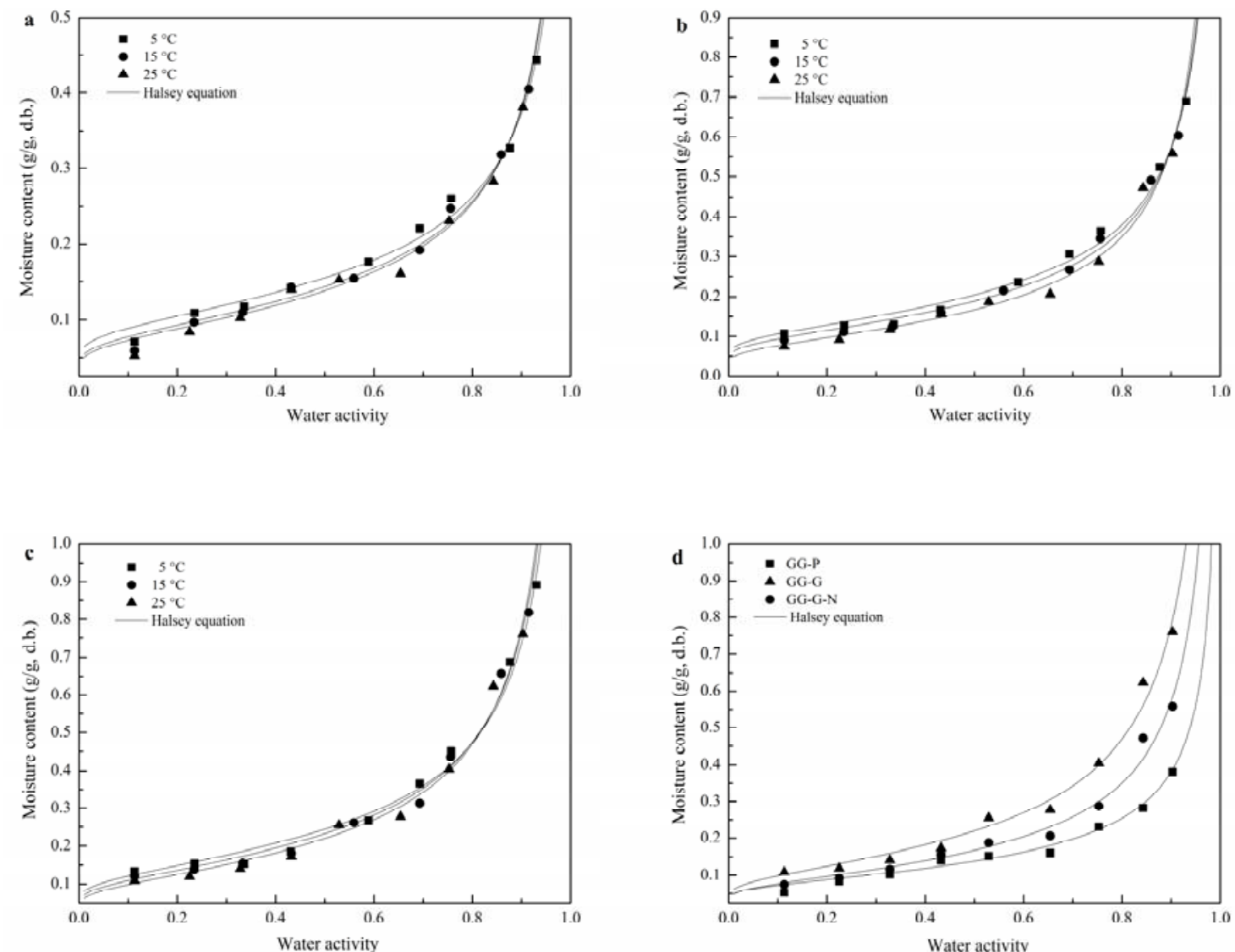

Figure 1. Moisture sorption isotherms of gum ghatti (GG)-based films at different temperatures; (a) GG-P, (b) GG-G, (c) GG-G-N, and (d) temperature of $25^{\circ} \mathrm{C}$. GG-P, pure gum ghatti film; GG-G, gum ghatti film with incorporation of glycerol; GG-G-N, gum ghatti film with incorporation of glycerol and nisin.

Table 2. Estimated parameters of the selected models fitted to sorption data of GG-based films at different temperatures.

\begin{tabular}{|c|c|c|c|c|c|c|c|c|c|c|}
\hline \multirow{2}{*}{ Model } & \multirow{2}{*}{ Parameter } & \multicolumn{9}{|c|}{ Temperature $\left({ }^{\circ} \mathrm{C}\right)$} \\
\hline & & GG-P & GG-G & GG-G-N & GG-P & GG-G & GG-G-N & GG-P & GG-G & GG-G-N \\
\hline \multirow{4}{*}{ GAB } & $X_{\mathrm{mg}}(\mathrm{g} / \mathrm{g})$ & 0.080 & 0.118 & 0.133 & 0.086 & 0.111 & 0.127 & 0.080 & 0.096 & 0.127 \\
\hline & $\mathrm{C}_{\mathrm{g}}$ & 20.00 & 24.23 & 23.41 & 21.67 & 16.51 & 31.91 & 19.90 & 15.62 & 13.72 \\
\hline & $\dot{K}$ & 0.87 & 0.92 & 0.93 & 0.86 & 0.90 & 0.93 & 0.87 & 0.92 & 0.92 \\
\hline & $\begin{array}{l}\text { Residual } \\
\text { pattern }\end{array}$ & & Scattered & & Scattered & Patterned & Scattered & \multicolumn{3}{|c|}{ Scattered } \\
\hline \multirow[b]{3}{*}{ Halsey } & $a$ & 0.013 & 0.0380 & 0.062 & 0.016 & 0.040 & 0.068 & 0.017 & 0.044 & 0.072 \\
\hline & $r$ & 2.148 & 1.830 & 1.709 & 1.942 & 1.709 & 1.587 & 1.836 & 1.537 & 1.493 \\
\hline & $R^{2}$ & 0.989 & 0.991 & 0.988 & 0.989 & 0.989 & 0.987 & 0.985 & 0.980 & 0.984 \\
\hline
\end{tabular}

Note: GG-P, pure gum ghatti film; GG-G, gum ghatti film with incorporation of glycerol; GG-G-N, gum ghatti film with incorporation of glycerol and nisin. 


\subsection{Thermodynamic Properties}

\subsubsection{Net Isosteric Heat of Sorption and Differential Entropy}

The variations of $q_{\mathrm{st}}$ versus the moisture content of GG-based films are shown in Figure 2a. The $q_{\mathrm{st}}$ decreased acutely at moisture content $<0.15 \mathrm{~g} / \mathrm{g}$, and relative slowly at moisture content ranging from 0.15 to $0.25 \mathrm{~g} / \mathrm{g}$. The decrease of $q_{\mathrm{st}}$ with increasing moisture content is a symbol of weak interactions between water and the surface of films. At a low moisture content level (e.g. in the monolayer region), water can be absorbed at the strongest binding sites on the film surface. With the increase of moisture content, the binding sites become occupied, and sorption occurs on the less available sites with lower binding energies [7]. The $q_{\mathrm{st}}$ approaches to 0 as the moisture content $>0.25 \mathrm{~g} / \mathrm{g}$, which indicates that sorption heat is nearly the same to the vaporization heat of free water [6]. At a low moisture content level (e.g., $<0.15 \mathrm{~g} / \mathrm{g}$ ), the highest $q_{\text {st }}$ values were observed for film GG-G, followed by GG-G-N and GG-P. The data imply that water molecules were strongly interacted with the sorption sites of GG-G and GG-G-N, compared with GG-P. However, the differences in $q_{\text {st }}$ values for GG-G and GG-G-N became negligible with increasing moisture content (Figure 2a). Furthermore, the binding forces are similar for all GG-based films when the moisture content was higher than $0.35 \mathrm{~g} / \mathrm{g}$. The value of $q_{\mathrm{st}}$ at a specific moisture content provides an indication of the state of the adsorbed water, and therefore a measure of the physical, chemical and microbiologic stability of the food material at given storage conditions. Furthermore, information about energy consumption and drying equipment design can also be obtained from the changes of the $q_{\mathrm{st}}$ with moisture content [9].
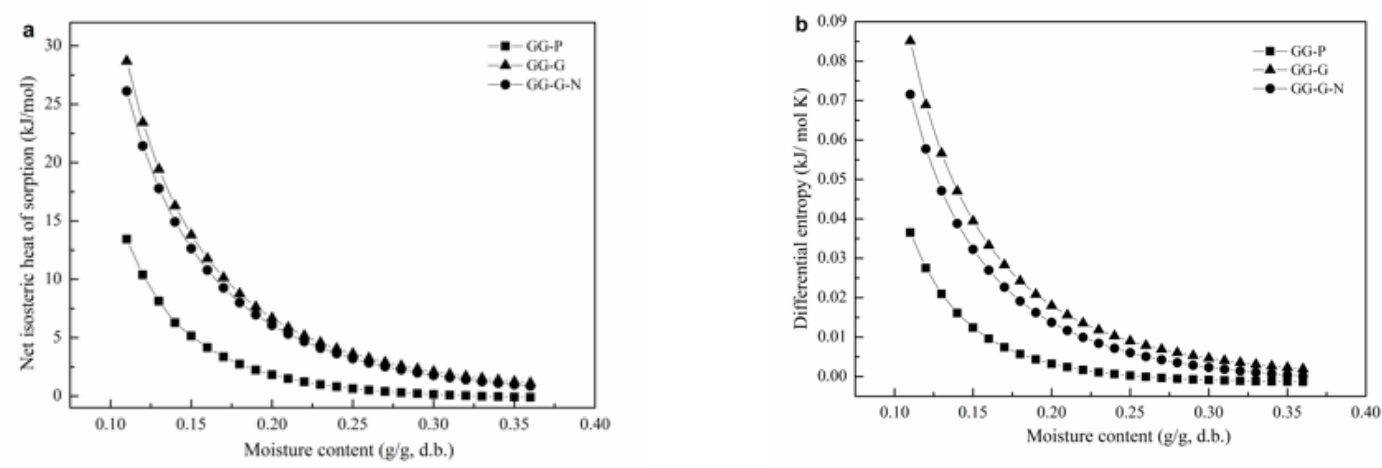

Figure 2. Net isosteric heat of sorption (a) and differential entropy (b) for GG-based films as a function of moisture content.

Figure $2 \mathrm{~b}$ shows the variation of $S_{\mathrm{d}}$ as a function of moisture content for GG-based films. Similar to the pattern of the $q_{\mathrm{st}}$, a strong dependence upon moisture content with an exponential trend are displayed for the $S_{\mathrm{d}}$ of GG-based films. The $S_{\mathrm{d}}$ decreased sharply to a moisture content of $0.15 \mathrm{~g} / \mathrm{g}$, and achieved a plateau when the moisture content continues to increase. The $S_{\mathrm{d}}$ value of GG-G and GG-G-N were higher than that of GG-P, irrespective of the moisture content. However, as moisture content became higher than $0.35 \mathrm{~g} / \mathrm{g}$, the differences significantly shortened. It is well known that sorption entropy is in proportion to the number of sorption sites at a specific energy level [30]. This work suggested that incorporation of glycerol and nisin can increase the number of available sorption sites of GG-based films.

\subsubsection{Enthalpy-entropy Compensation Theory}

Enthalpy-entropy compensation theory (isokinetic theory) is commonly employed to evaluate polymers' physical and chemical phenomenon such as moisture sorption [24,27]. This theory is of vital importance to assess whether there is greater molecular interaction or to the link of the molecules in the system; enthalpy-driven means the matrix forms larger organization or order over disorganization, whereas entropy-driven implies there is greater freedom of the molecules in the food [31]. This 
theory illustrates that compensation phenomenon emerges due to variations in the sorbate-sorbent interactions. The enthalpy-entropy relationships of GG-based films are shown in Table 3, in which a linear relation between these variables was observed with a high regression coefficient $\left(R^{2}=0.999\right)$, implying the applicability of the enthalpy-entropy compensation theory for the sorption behaviors of GG-based films in the investigated moisture contents. The $T_{\beta}$ values calculated from Eq. (7) were 359.3, 332.4 and $355.2 \mathrm{~K}$ for the sorption of GG-P, GG-G and GG-G-N, respectively. However, a linear relationship between $q_{\mathrm{st}}$ and $S_{\mathrm{d}}$ does not necessarily mean that the compensation theory is applicable. To determine the validity of the compensation theory, the $T_{\mathrm{hm}}$ value was calculated and compared with the $T_{\beta}$. The compensation theory exists, provided that $T_{\mathrm{hm}}$ is significantly different from $T_{\beta}$ [26]. The value of $T_{\mathrm{hm}}(297.9 \mathrm{~K})$, which is significantly $(p<0.05)$ different from the values of $T_{\beta}$, verifies the applicability of the compensation theory for the moisture sorption of GG-based films. In addition, the moisture sorption process for all tested films within the examined moisture ranges was considered as enthalpy-driven, because the $T_{\beta}$ values were much higher than the $T_{\mathrm{hm}}$ value. It was reported that enthalpy-controlled behaviors depend upon food ingredients; nevertheless, entropy-controlled behaviors rely mainly on the microstructure of the matrix [22]. These observations imply that the microstructure of the GG-based films was stable in the process of moisture sorption within the temperature range from 5 to $25^{\circ} \mathrm{C}$. Furthermore, the addition of glycerol and nisin merely altered the chemical composition of GG film, and did not alter its microstructure.

Table 3. Characteristics parameters for enthalpy-entropy relationships for sorption of GG-based films.

\begin{tabular}{cccc}
\hline Samples & $\boldsymbol{T}_{\boldsymbol{\beta}}(\boldsymbol{K})$ & $\boldsymbol{\Delta} G_{\boldsymbol{\beta}}(\mathbf{k J} / \mathbf{m o l})$ & $\boldsymbol{R}^{\mathbf{2}}$ \\
\hline GG-P & 359.3 & 535.0 & 0.999 \\
GG-G & 332.4 & 598.6 & 0.999 \\
GG-G-N & 335.2 & 1031.6 & 0.999 \\
\hline
\end{tabular}

Note: GG-P, pure gum ghatti film; GG-G, gum ghatti film with incorporation of glycerol; GG-G-N, gum ghatti film with incorporation of glycerol and nisin.

Furthermore, since $\Delta G$ can be used as a symbol of the sorbent-water affinity, it also provides a rule concerning whether the water sorption behavior is a spontaneous or non-spontaneous feature [7]. The $\Delta G$ values of GG-P, GG-G and GG-G-N were $535.0,598.6$ and $1031.6 \mathrm{~kJ} / \mathrm{mol}$, respectively. These results indicated that the moisture sorption processes of GG-based films were non-spontaneous, suggesting that the GG-based films do not absorb water from the environment spontaneously, which is desirable because the product is stable [25]. Cefalas et al. [32] and Gavriil et al. [33] discovered that an entropic potential alternation competes with a thermodynamic potential from the electric dipole attachment of molecular adsorbates in polymeric ligands and the power of an associated entropic nanothermodynamic potential is proportional to the number of nanocavities induced by photon treatment. Therefore, to properly understand the water sorption mechanism, both enthalpy-entropy compensation and competition theory should be considered in future research.

\subsubsection{Spreading Pressure}

The force parallel to the surface that should be imposed perpendicular to each unit length of edge to prevent the surface from spreading is termed as $\varphi$ [22]. It is reported that high $\varphi$ values indicate a high-water molecule-active site affinity, and the more hygroscopic the product is, the higher value the $\varphi$ will be $[25,34]$.

The $\varphi$ of isotherms of GG-based films at different temperatures and $a_{\mathrm{w}}$ are shown in Figure 3, where the $\varphi$ was increased with increasing $a_{\mathrm{w}}$ and decreased with increasing temperature at a specific $a_{\mathrm{w}}$. Similar trends have been reported in pullulan-sodium alginate-based films [7]. The $\varphi$ values of GG-G and GG-G-N were higher than those of pure GG films. This might be owing to the modifications in the conformation and/or topology of the GG molecules and/or the ratio of hydrophilic/hydrophobic sites adsorbed at the interface of GG-based films caused by incorporation of glycerol and nisin. 

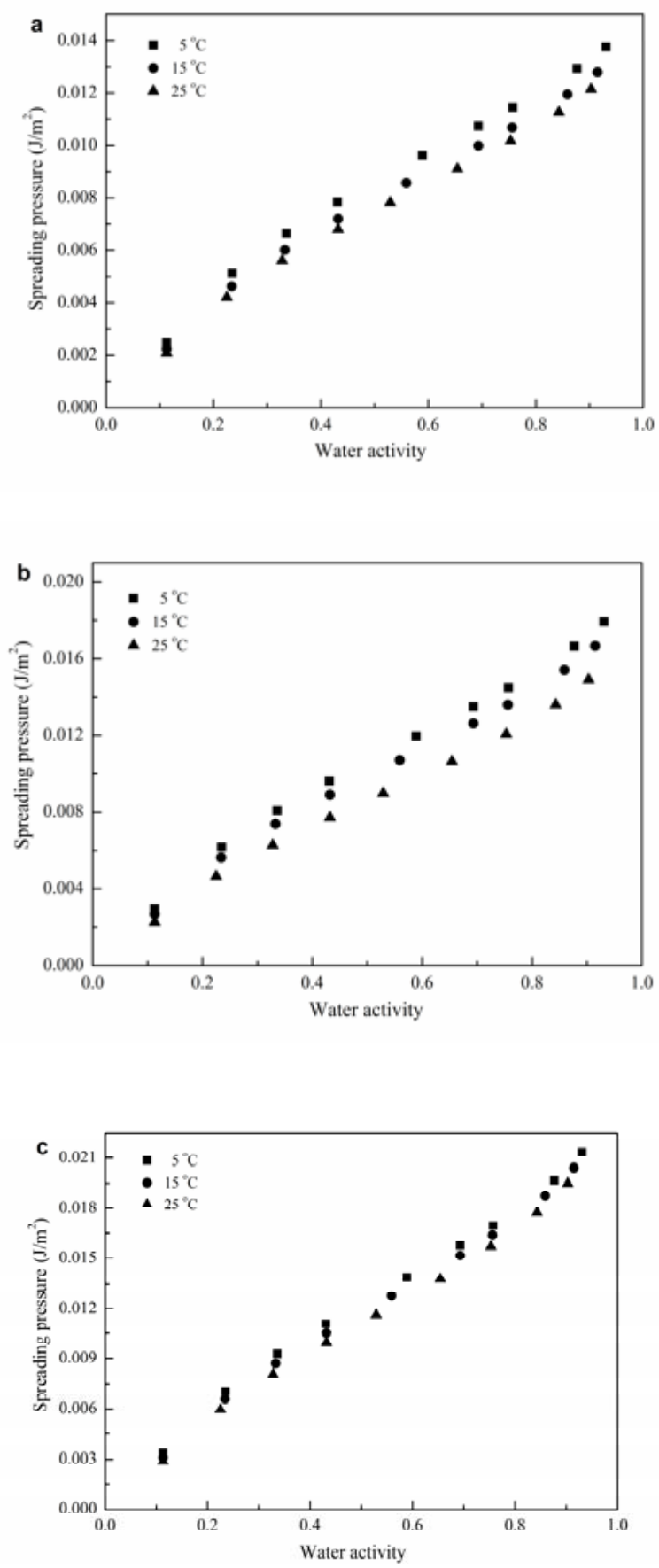

Figure 3. Spreading pressure as a function of water activity of for GG-based films at different values of water activity; (a) GG-P, (b) GG-G, and (c) GG-G-N.

\subsection{Glass Transition Temperature $\left(T_{g}\right)$}

Figure 4 shows the fluctuation of $T_{\mathrm{g}}$ as a function of moisture content for GG-based films. The $T_{\mathrm{g}}$ was decreased with increasing moisture content for all GG-based films. $T_{\mathrm{g}}$ of GG-P was decreased linearly from 49.3 to $-10.5^{\circ} \mathrm{C}$ as the moisture content increased from 0.050 to $0.276 \mathrm{~g} / \mathrm{g}$. However, for GG-G-N film, $T_{\mathrm{g}}$ was decreased linearly from 46.6 to $-25.7^{\circ} \mathrm{C}$ as the moisture content increased from 0.098 to $0.432 \mathrm{~g} / \mathrm{g}$. The anticipated decrease of $T_{\mathrm{g}}$ with the increasing moisture content can be attributed to the plasticization effect of water, which signifies a decrease in the mean molecular weight in the food system and the corresponding increase in the molecular mobility of the amorphous constituents in the matrix [5]. The $T_{\mathrm{g}}$ of food polymers depend mainly on the water content, food 
ingredients and mean molecular weight of the solutes existed in the food system [12]. Therefore, the $T_{\mathrm{g}}$ of polymers is decreased by the incorporation of low molecular weight components and increased by the incorporation of high molecular weight additives compatible with the food solids. As moisture content is close to $0.220 \mathrm{~g} / \mathrm{g}$, the $T_{\mathrm{g}}$ values for GG-P, GG-G and GG-G-N were $-4.2,-6.7$ and $20.5^{\circ} \mathrm{C}$, respectively. This was a reasonable due to the plasticizer characteristics of glycerol, which decreased the mean molecular weight in the system and influenced the molecular mobility and mechanical characteristics of the films [5]. However, for the GG-G-N films, the anti-plasticization effect of nisin was observed, which increased the mean molecular weight in the matrix and decreased the molecular mobility, and affected the mechanical properties of the films.

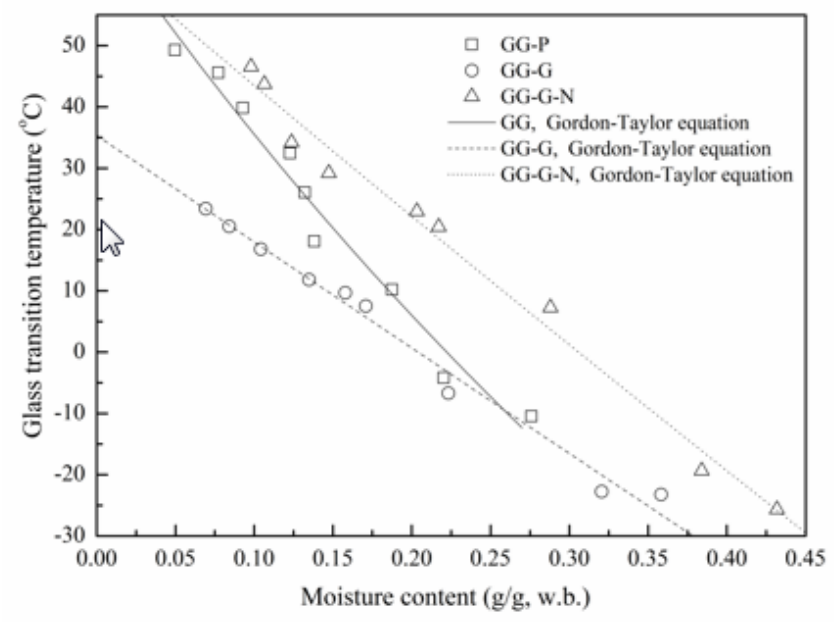

Figure 4. Effect of moisture content on the glass transition temperature of GG-based films.

The $T_{\mathrm{g}}$ data of plasticized films was employed to fit the Gordon-Taylor equation and the $T_{\mathrm{gs}}$ values for GG-P, GG-G and GG-G-N were found to be $71.5,31.0$ and $63.6^{\circ} \mathrm{C}$, respectively. The prominent declining effect of glycerol on $T_{\mathrm{g}}$ was observed. However, with the incorporation of nisin, the $T_{\mathrm{g}}$ of GG-G was increased from 31.0 to $63.6^{\circ} \mathrm{C}$. The parameter $k$ means the strength of the biopolymer-water interaction. For a binary mixture, a larger $k$ indicates that the solids are more easily plasticized by water than food mixtures with a smaller $k$ and equivalent water content [12]. The $k$ value of GG-P was decreased with the addition of glycerol and nisin in the film-forming solution. The $k$ values for GG-P, GG-G and GG-G-N were 1.99, 0.93 and 1.12, respectively. The $k$ value was the smallest in the merely glycerol-containing film (GG-G), but was increased when nisin was incorporated in the GG-G film-forming solutions. The results showed that nisin interacted with the GG-G matrix and modified the water plasticization behavior. A similar trend has been reported by Fabra et al. [5] for sodium caseinate films as affected by lipid (oleic acid and beeswax).

\subsection{State Diagram of GG-Based Films}

The state diagram describes the physical state as well as state transitions of foods, which can be chosen as valuable tools in selecting the suitable temperature and moisture content condition for their manipulation and storage [35]. Recently, water activity and glass transition theories are combined to provide a unified stability evaluation criterion for foods [35]. Therefore, the sorption isotherms and $T_{\mathrm{g}}$ of GG-based films were merged to evaluate the critical parameters (viz. CWC and CWA) of films (Figure 5a). At the temperature of $10^{\circ} \mathrm{C}$ (assuming this is the temperature used for the storage of GG-based film packaged foods), the CWC for the glass transition of GG-P, calculated from the Gordon-Taylor equation, was $0.185 \mathrm{~g} / \mathrm{g}$. The corresponding CWA was then acquired from the Halsey equation, and the value was calculated to be 0.762 , which suggested that the maximum ERH that could ensure the glassy state of the films throughout the storage is $76.2 \%$. Similarly, the CWC and CWA for GG-G and GG-G-N at $10^{\circ} \mathrm{C}$ were calculated to be $0.145,0.258 \mathrm{~g} / \mathrm{g}$ and $0.639,0.790$, respectively 
(Figure $5 b, c)$. This outcome suggested that at the same storage and/or transport temperature, the CWC and CWA of pure GG film was decreased with the incorporation of glycerol, and increased with the incorporation of nisin. If the GG-based films are applied for the packaging of fresh foods (such as fruits, vegetables and aquatic products), the CWC and ERH of pure GG film that guarantee the maximum mechanical and physicochemical properties might decrease for GG-G films and increase for GG-G-N films. That is, the storage stability/shelf life of GG-G-N packaged fresh foods is the highest; whereas GG-G packaged fresh foods possess the lowest shelf life compared with the GG-P and GG-G-N packaged pattern. Using a more specific example to explain: If the perishable foods (such as fruits and vegetables) are packaged by GG-G films and stored at $10{ }^{\circ} \mathrm{C}$, and the ERH is controlled at $90 \%$, which is much higher than the CWA of GG-G films. Under this circumstance, the film is in the rubbery state which promotes the molecular mobility, accelerates the permeability and reduces mechanical properties, and therefore leads to decreased perseveration [6,36]. The increased CWA and CWC of GG-G-N imply a potentially improved preservation effect when the films are employed in edible film packaging. The state diagram constructed in this study can be employed to assess the relationship between the $T_{\mathrm{g}}$ and some physicochemical and mechanical properties (such as oxygen and water vapor permeability, tensile strength, elongation at break, etc.) of films during dehydration (films making) and utilization as packaging materials (films application) for perishable foods (such as fruit and vegetables, aquatic products, etc.).
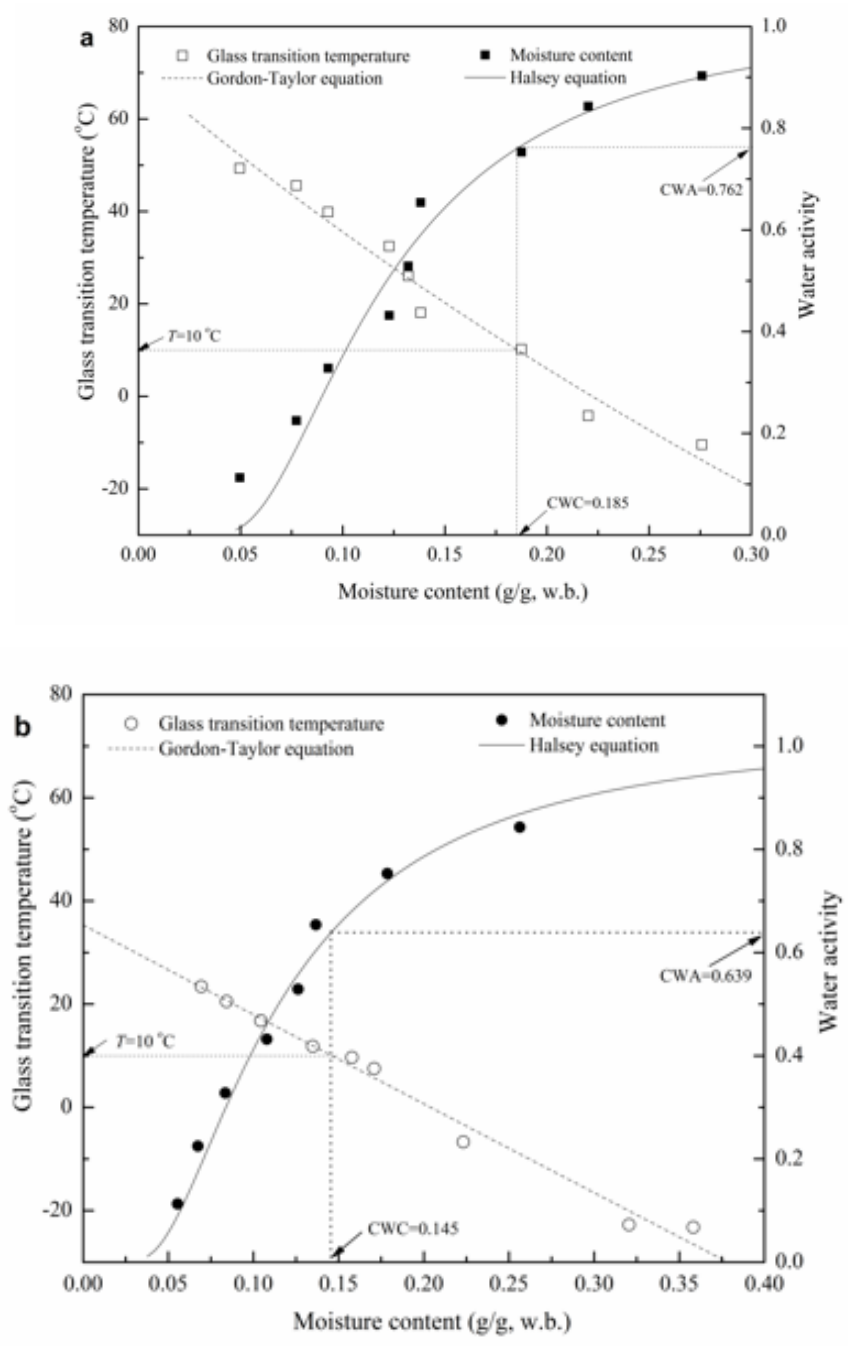

Figure 5. Cont. 


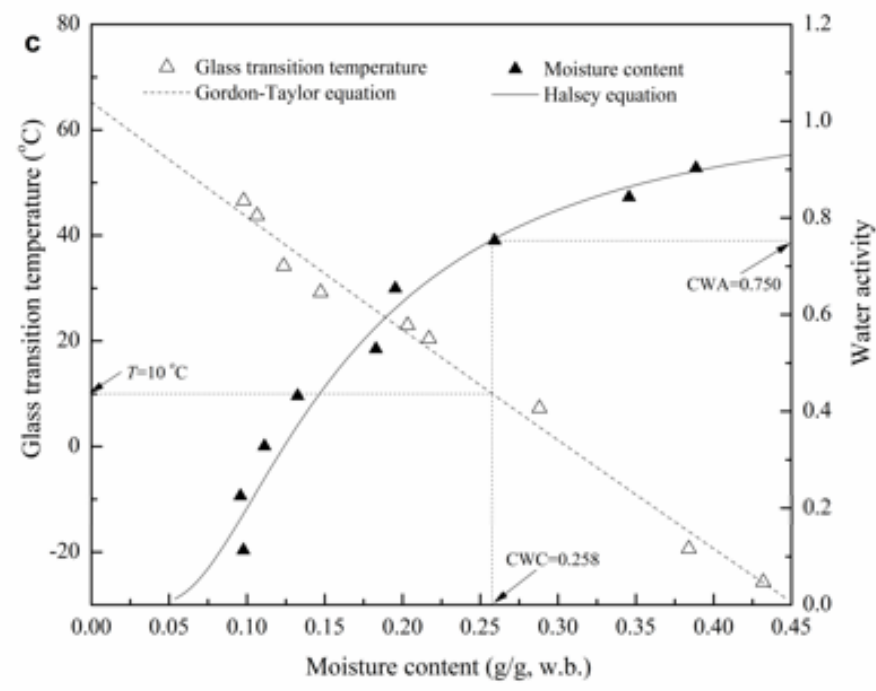

Figure 5. Variation of glass transition temperature, water activity with moisture content of GG-based films; (a) GG-P, (b) GG-G, and (c) GG-G-N.

\section{Conclusions}

The MSI of GG-based films followed typical type III isotherms. Compared with GG-P, the incorporation of glycerol and nisin increased the sorption ability of films. The $q_{\mathrm{st}}$ and $S_{\mathrm{d}}$ were deceased markedly up to a moisture content of $0.15 \mathrm{~g} / \mathrm{g}$, and arrived at a steady state as the moisture content further increased. The $\varphi$ was increased with increasing $a_{\mathrm{w}}$ and decreased with higher temperature. Compared with GG-P, an incorporation of glycerol and nisin increased the $q_{\mathrm{st}}, S_{\mathrm{d}}$ and $\varphi$ of films, especially at moisture content below $0.15 \mathrm{~g} / \mathrm{g}$. The sorption mechanism in GG-based films was enthalpy-driven and non-spontaneous. The plasticization of GG-based films by glycerol and adsorbed water molecules on polymeric chains were observed.

The state diagram of films revealed that at a determined temperature, the CWC and CWA of GG-P were decreased with the incorporation of glycerol and increased with the incorporation of nisin. To have a more in-depth understanding on water thermodynamic and thermal properties, and to investigate their effects on the physicochemical properties of packaged foods, further research should be carried out on the effects of moisture content and/or the internal environmental ERH of films on their physicochemical, mechanical and microstructure properties at different temperatures, such as $T$ $>>T_{\mathrm{g}}, T \approx T_{\mathrm{g}}, T<<T_{\mathrm{g}}$.

Author Contributions: Conceptualization, Q.S.; methodology, Q.S.; software, P.Z. and X.Z.; validation, Y.Z. and X.Z.; formal analysis, P.Z. and Q.S.; investigation, P.Z. and Y.Z.; resources, Y.Z. and L.Z.; data curation, P.Z. and Y.Z.; writing—original draft preparation, Y.Z. and Q.S.; writing - review and editing, Q.S. and Z.F.; visualization, Y.Z. and Q.S.; supervision, Q.S.; project administration, Q.S. All authors have read and agreed to the published version of the manuscript.

Funding: This research received no external funding.

Conflicts of Interest: The authors declare no conflict of interest.

\section{References}

1. Arcan, I.; Yemenicioğlu, A. Incorporating phenolic compounds opens a new perspective to use zein films as flexible bioactive packaging materials. Food Res. Int. 2011, 44, 550-556. [CrossRef]

2. Fang, Z.; Zhao, Y.; Warner, R.D.; Stuart, J. Active and intelligent packaging in meat industry. Trends Food Sci. Technol. 2017, 61, 60-71. [CrossRef]

3. Nieto, M.B. Structure and Function of Polysaccharide Gum-Based Edible Films and Coating. In Edible Films and Coatings for Food Applications; Springer: New York, NY, USA, 2009; pp. 57-112. 
4. Zhang, P.; Zhao, Y.; Shi, Q. Characterization of a novel edible film based on gum ghatti: Effect of plasticizer type and concentration. Carbohydr. Polym. 2016, 153, 345-355. [CrossRef]

5. Fabra, M.J.; Talens, P.; Chiralt, A. Water sorption isotherms and phase transitions of sodium caseinate-lipid films as affected by lipid interactions. Food Hydrocoll. 2010, 24, 384-391. [CrossRef]

6. Rhim, J.W.; Lee, J.H. Thermodynamic analysis of water vapor sorption isotherms and mechanical properties of selected paper-based food packaging materials. J. Food Sci. 2009, 74, E502-E511. [CrossRef]

7. Xiao, Q.; Tong, Q. Thermodynamic properties of moisture sorption in pullulan-sodium alginate based edible films. Food Res. Int. 2013, 54, 1605-1612. [CrossRef]

8. Al-Muhtaseb, A.H.; McMinn, W.A.M.; Magee, T.R.A. Moisture sorption isotherm characteristics of food products: A review. Food Bioprod. Process 2002, 80, 118-128. [CrossRef]

9. McMinn, W.A.M.; Magee, T.R.A. Thermodynamic properties of moisture sorption of potato. J. Food Eng. 2003, 60, 157-165. [CrossRef]

10. Bonilla, E.; Azuara, E.; Beristain, C.I.; Vernon-Carter, E.J. Predicting suitable storage conditions for spray-dried microcapsules formed with different biopolymer matrices. Food Hydrocoll. 2010, 24, 633-640. [CrossRef]

11. Biliaderis, C.G.; Lazaridou, A.; Arvanitoyannis, I. Glass transition and physical properties of polyol-plasticised pullulan-starch blends at low moisture. Carbohydr. Polym. 1999, 40, 29-47. [CrossRef]

12. Sablani, S.S.; Syamaladevi, R.M.; Swanson, B.G. A review of methods, data and applications of state diagram of food systems. Food Eng. Rev. 2010, 2, 168-203. [CrossRef]

13. Shi, Q.; Lin, W.; Zhao, Y.; Zhang, P. Thermal characteristics and state diagram of Penaeus vannamei meat with and without maltodextrin addition. Thermochim. Acta 2015, 616, 92-99. [CrossRef]

14. Arfat, Y.A. Plasticizers for Biopolymer Films. In Glass Transition and Phase Transition in Food and Biological Materials; Ahmed, J., Ed.; Wiley: Hoboken, NJ, USA, 2017.

15. Kurek, M.; Guinault, A.; Voilley, A.; Galic, K.; Debeaufort, F. Effect of relative humidity on carvacrol release and permeation properties of chitosan based films and coatings. Food Chem. 2014, 144, 9-17. [CrossRef] [PubMed]

16. Remedio, L.N.; Silva dos Santos, J.W.; Vieira Maciel, V.B.; Yoshida, C.M.P.; Aparecida de Carvalho, R. Characterization of active chitosan films as a vehicle of potassium sorbate or nisin antimicrobial agents. Food Hydrocoll. 2019, 87, 830-838. [CrossRef]

17. Marvdashti, L.M.; Koocheki, A.; Yavarmanesh, M. Characterization, release profile and antimicrobial properties of bioactive polyvinyl alcohol-Alyssum homolocarpum seed gum-nisin composite film. Food Biophys. 2019, 14, 120-131. [CrossRef]

18. Aguirre-Loredo, R.Y.; Rodriguez-Hernandez, A.I.; Velazquez, G. Modelling the effect of temperature on the water sorption isotherms of chitosan films. Food Sci. Technol. 2016, 37, 112-118. [CrossRef]

19. Zhao, Y.; Zhang, P.; Shi, Q. Effect of Nisin on the properties of edible films prepared by gum ghatti. Sci. Technol. Food Ind. 2017, 38, 69-73.

20. Greenspan, L. Humidity fixed points of binary saturated aqueous solutions. J. Res. Natl. Bur. Stand. Sect. A 1977, 81, 89-102. [CrossRef]

21. McLaughlin, C.P.; Magee, T.R.A. The determination of sorption isotherm and the isosteric heats of sorption for potatoes. J. Food Eng. 1998, 35, 267-280. [CrossRef]

22. Shi, Q.; Lin, W.; Zhao, Y.; Zhang, P.; Wang, R. Moisture adsorption isotherms and thermodynamic properties of Penaeus vannamei meat with and without maltodextrin addition. J. Aquat. Food Prod. Technol. 2016, 25, 1348-1367. [CrossRef]

23. Moreira, R.; Chenlo, F.; Torres, M.D.; Vallejo, N. Thermodynamic analysis of experimental sorption isotherms of loquat and quince fruits. J. Food Eng. 2008, 88, 514-521. [CrossRef]

24. Noshad, M.; Mohebbi, M.; Shahidi, F.; Mortazavi, S.A. Effect of osmosis and ultrasound pretreatment on the moisture adsorption isotherms of quince. Food Bioprod. Process. 2012, 90, 266-274. [CrossRef]

25. Lago, C.C.; Liendo-Cárdenas, M.; Noreña, C.P.Z. Thermodynamic sorption properties of potato and sweet potato flakes. Food Bioprod. Process. 2013, 91, 389-395. [CrossRef]

26. Krug, R.R.; Hunter, W.G.; Grieger, R.A. Enthalpy-entropy compensation. 2. Separation of the chemical from the statistical effect. J. Phys. Chem. 1976, 80, 2341-2351. [CrossRef]

27. McMinn, W.A.M.; Al-Muhtaseb, A.H.; Magee, T.R.A. Enthalpy-entropy compensation in sorption phenomena of starch materials. Food Res. Int. 2005, 38, 505-510. [CrossRef] 
28. Alpizar-Reyes, E.; Carrillo-Navas, H.; Romero-Romero, R.; Varela-Guerrero, V.; Alvarez-Ramírez, J.; Pérez-Alonso, C. Thermodynamic sorption properties and glass transition temperature of tamarind seed mucilage (Tamarindus indica L.). Food Bioprod. Process. 2017, 101, 166-176. [CrossRef]

29. Brett, B.; Figueroa, M.; Sandoval, A.J.; Barreiro, J.A.; Müller, A.J. Moisture sorption characteristics of starchy products: Oat flour and rice flour. Food Biophys. 2009, 4, 151-157. [CrossRef]

30. Toğrul, H.; Arslan, N. Moisture sorption behaviour and thermodynamic characteristics of rice stored in a chamber under controlled humidity. Biosyst. Eng. 2006, 95, 181-195. [CrossRef]

31. Spada, J.C.; Noreña, C.P.Z.; Marczak, L.D.F.; Tessaro, I.C. Water adsorption isotherms of microcapsules with hydrolyzed pinhão (Araucaria angustifolia seeds) starch as wall material. J. Food Eng. 2013, 114, 64-69. [CrossRef]

32. Cefalas, A.C.; Sarantopoulou, E.; Kollia, Z.; Kitsara, M.; Raptis, I.; Bakalis, E. Entropic nanothermodynamic potential from molecular trapping within photon induced nano-coids in photon processed PDMS layer. Soft Matter 2012, 8, 5561-5574. [CrossRef]

33. Gavriil, V.; Chatzichristidi, M.; Kollia, Z.; Cefalas, A.C.; Spyropoulos-Antonakakis, N.; Semashko, V.V.; Sarantopoulou, E. Photos probe entropic potential variation during molecular confinement in nanocavities. Entropy 2018, 20, 545. [CrossRef]

34. Torres, M.D.; Moreira, R.; Chenlo, F.; Vazquez, M.J. Water adsorption isotherms of carboxymethyl cellulose, guar, locust bean, tragacanth and xanthan gums. Carbohydr. Polym. 2012, 89, 592-598. [CrossRef] [PubMed]

35. Rahman, M.S. Food stability determination by macro-micro region concept in the state diagram and by defining a critical temperature. J. Food Eng. 2010, 99, 402-416. [CrossRef]

36. Xiao, Q.; Lim, L.-T.; Tong, Q. Properties of pullulan-based blend films as affected by alginate content and relative humidity. Carbohydr. Polym. 2012, 87, 227-234. [CrossRef]

(C) 2020 by the authors. Licensee MDPI, Basel, Switzerland. This article is an open access article distributed under the terms and conditions of the Creative Commons Attribution (CC BY) license (http://creativecommons.org/licenses/by/4.0/). 